Mawaizh

Jurnal Dakwah dan Pengembangan Sosial Kemanusiaan

Vol. 9, no. 2 (2018), pp. 224-238.

DOI: https://doi.org/10.32923/maw.v9i2.799

\title{
Kebebasan Berdakwah di Youtube: Suatu Analisis Pola Partisipasi Media
}

\section{Ari Wibowo}

IAIN Syaikh Abdurrahman Siddik Bangka Belitung, Indonesia ari.wibowo3@yahoo.com

\begin{abstract}
This article describes the reality of freedom of preaching on social media. The research approach used in this study is qualitative descriptive with a critical paradigm. There are two focus of the study approach used, namely; 1) participatory culture approach, to know the characteristics of the Youtube da'wah channel, 2) a new media impact analysis approach, to analyze the problem of da'i and mad'u millennial in the context of da'wah activities on the Youtube channel. The results of this study indicate that da'wah activities on the da'wah Youtube channel consist of 4 (four) types, namely: 1) Youtube channels affiliated with community organizations; 2) Youtube channels that are managed independently by da'i;3) youtube channel managed by da'wah community; 4) Youtube channels managed by Vloggers or other Youtuber. Also, there are threats behind the freedom to preach on social media, including; easy spread of provocative preaching messages, slander, hoax, and veiled radical understanding. The solution to the threat is; 1 ) the corrective approach of the da'i through Youtube channels; 2) the participation of da'i affiliates to oversee da'wah content that is inappropriate and contrary to humanist, moderate and transformative da'wah.
\end{abstract}

Keywords; Da'wah, Social Media, Youtube, Participatory Culture, Da'i and Mad'u Milenial.

\begin{abstract}
Abstrak; Tulisan ini menguraikan tentang realita kebebasan berdakwah di media sosial. Pendekatan penelitian yang digunakan dalam penelitian ini bersifat kualitatif deskriptif dengan paradigma kritis. Ada dua fokus pendekatan kajian yang digunakan yakni; 1) pendekatan participatory culture, untuk mengetahui karakteristik channel Youtube dakwah, 2) pendekatan analisis dampak media baru, untuk menganalisis problematika da'i dan mad'u milenial dalam konteks aktifitas dakwah di channel Youtube. Hasil dari penelitian ini menunjukkan bahwa aktifitas dakwah di channel Youtube dakwah terdiri dari 4 (empat) tipe, yaitu: 1) channel Youtube afiliasi da'i dengan organisasi kemasyarakatan; 2) channel Youtube yang dikelola secara mandiri (official) oleh da'í; 3) channel youtube yang dikelola oleh komunitas dakwah; 4) channel Youtube yang dikelola oleh Vloger atau Youtuber lain. Selain itu ada ancaman dibalik kebebasan berdakwah di media sosial, diantaranya; mudahnya tersebar pesan-pesan dakwah provokatif, fitnah, hoaks, dan pemahaman radikal yang terselubung. Solusi untuk menghadapi ancaman itu adalah; 1) pendekatan korektif para da'i melalui channel Youtube; 2) peran serta da'i afiliasi untuk mengawasi konten dakwah yang tidak sesuai dan bertentangan dengan dakwah yang humanis, moderat, dan transformatif.
\end{abstract}

Kata kunci; Dakwah, media sosial, Youtube, Kultur Partisipatoris, Da'i dan Mad'u milenial. 


\section{A. Pendahuluan}

ktivitas dakwah saat ini tengah berhadapan dengan masyarakat informasi yang
diidentikan dengan tingkat konsumsi media sosial (medsos) yang sangat tinggi.
Dibuktikan dengan beredarnya arus informasi dalam berbagai bentuk (artificial intelligent) yang berkembang dilingkungan komunikasi mereka. Jaringan informasi itupun tidak hanya diorganisir dan dimanfaatkan oleh pihak-pihak tertentu saja, tetapi semua elemen masyarakat mendapatkan kebebasan dan hak yang sama untuk membuat, mengolah dan menyebarluaskan segala bentuk informasi.

Berkat teknologi baru seperti jaringan internet yang tersistem dalam perangkat mobile juga telah memenuhi kebutuhan hidup mereka. Seperti kebutuhan untuk berinteraksi sosial, mencari data, dan sampai kepada kepentingan untuk menikmati hiburan. Pada saat ini jaringan internet lebih dimanfaatkan sebagai media sosial oleh masyarakat. ${ }^{1}$ Akses media sosial telah membuat kehidupan dunia nyata (sesuai realita) ditransformasi ke dunia maya (artificial). Aktivitas dakwah yang semula berlangsung secara konvensional (dari masjid ke masjid) telah berubah menjadi aktivitas dakwah bermedia digital (dakwah digital).

Konten dakwah digital pun dapat diakses oleh masyarakat sesuai keinginananya. Begitu juga kebutuhan informasi dan berkomunikasi dengan banyak orang di tempat yang berbeda dapat terpenuhi, tanpa memikirkan beban dan tekanan dalam hal waktu dan materi. Tapi perlu disadari bahwa dibalik berbagai kemudahan akses media tersebut, terdapat masalah besar yang berakibat negatif pada penggunannya.

Kementerian Komunikasi dan Informasi Republik Indonesia (Kemenkominfo RI) melalui Tim AIS Subdit Pengendalian Konten Ditjen Aplikasi Informatika telah memverifikasi dan memvalidasi banyaknya konten digital yang berisi berita bohong (hoax) dan ujaran kebencian (hate speech). Dari banyaknya konten tersebut ada yang terkait dengan konten fitnah, dan konten terkait isu-isu agama. ${ }^{2}$ Pelaku penyebaran konten digital tersebut berasal dari kalangan terdidik dan terpelajar, bahkan ada diantaranya terkenal sebagai pendakwah yang konten dakwahnya sering dipublikasikan di berbagai jejaring sosial (Youtube, Facebook, Whatsapp, Instagram, dan lain-lain).

\footnotetext{
${ }^{1}$ Baidu, Jelajah Dunia Mobile di Indonesia (Jakarta: Baidu Indonesia, 2014), p. 15.

2 Budi Prayitno, 'Langkah Pemerintah Menangkal Diseminasi Berita Palsu,' Jurnal Wacana Kinerja: Kajian Praktis-Akademis Kinerja dan Administrasi Pelayanan Publik, vol. 20, no. 2 (2018), pp. 17-40.
} 
Tidak dapat dipungkiri bahwa jejaring sosial dalam berbagai bentuk memberikan kebebasan bagi para pendakwah untuk berekspresi. Pesan-pesan dakwah yang disalurkan melalu media sosial begitu cepat diterima oleh objek dakwah (mad'u) dan meluas. Bahkan pesan-pesan tersebut terdokumentasi secara digital (digital footprintjejak digital). Di sinilah para pendakwah harus selektif dalam bertutur kata, jangan sampai kesalahan tutur berakibat pada tindakan yang melanggar hukum dan bertentangan dengan etika komunikasi dakwah.

Kemudahan berdakwah dan menerima pesan dakwah secara virtual juga mengakibatkan penggunanya menjadi ketergantungan. Dalam pandangan Teori Ketergantungan dan Kecemasan sosial dijelaskan bahwa ketergantungan erat hubungannya dengan upaya pemenuhan kebutuhan atau pencapaian tujuan dengan bergantung pada media sosial. ${ }^{3}$ Media tersebut dijadikan satu-satunya cara cepat untuk mendapatkan pemahaman agama Islam. Mereka tidak perlu bersusah payah pergi ke tempat-tempat pengajian untuk mendapatkan pengajaran langsung, cukup berbekal sebuah gawai (gadget) bisa mengakses kajian Islam dengan beragam tema yang bisa dipilih sesuai kehendaknya.

Telah banyak masyarakat yang terperangkap oleh kemudahan yang ditawarkan oleh media sosial. Mereka sepenuhnya percaya pada sajian media sosial dan cenderung pada pembenaran subjektif. Ketika menyukai seorang ustadz ( $\left.d a^{\prime} i\right)$ tertentu, maka apapun yang disampaikan oleh ustadz tersebut akan diterima sebagai satu-satunya kebenaran dan menolak kebenaran yang lainnya. Seperti halnya yang diungkap Neil Postman, bahwa kehadiran media sosial memicu munculnya perilaku technopoly yang berarti perilaku masyarakat memiliki kecenderungan terhadap media sosial, sehingga media sosial tersebut mengendalikan semua aspek kehidupannya. ${ }^{4}$

Keterikatan dan ketergantungan terhadap teknologi menjadi tantangan bagi para da'i untuk mengaktualisasikan dakwahnya ditengah masyarakat informasi. Ada banyak perangkat teknologi dalam media sosial yang menjadi media dakwah. Salah satu media sosial yang memiliki layanan digital (fitur) yang menarik bagi dakwah digital adalah "YouTube". Terbukti dari meningkatnya jumlah pengguna (user) disetiap tahun.

${ }^{3}$ Andrew Shrock, My space Or Our Space: A Media System Dependency View Of My Space, Thesis (Florida: University Of Central Florida, 2006), p. 4.

4 Joseph Straubhaar, Robert Larose and Lucinda Davenport, Media Now: Understanding, Media, Culture, and Technology (United State Of Amerika: Thomson-Wadsworth, 2010), p. 50 
Tabel 1.

Platforms media sosial paling aktif di Indonesia.

\begin{tabular}{|c|l|c|c|c|}
\hline \multirow{2}{*}{ No } & \multirow{2}{*}{ Media Sosial } & \multicolumn{2}{c|}{$\begin{array}{c}\text { Persentase Penetrasi } \\
\text { Pengguna }\end{array}$} & \multirow{2}{*}{$\begin{array}{c}\text { Kenser } \\
\text { Penaikan }\end{array}$} \\
\cline { 3 - 5 } & & $\begin{array}{c}\text { Per- Jan } \\
2018\end{array}$ & $\begin{array}{c}\text { Per- Jan } \\
2019\end{array}$ & \\
\hline 1 & Youtube & $43 \%$ & $88 \%$ & $45 \%$ \\
\hline 2 & Whatsapp & $41 \%$ & $83 \%$ & $42 \%$ \\
\hline 3 & Facebook & $40 \%$ & $81 \%$ & $41 \%$ \\
\hline 4 & Instagram & $38 \%$ & $80 \%$ & $42 \%$ \\
\hline 5 & Line & $33 \%$ & $59 \%$ & $26 \%$ \\
\hline 6 & Twitter & $27 \%$ & $52 \%$ & $25 \%$ \\
\hline 7 & FB Messenger & $24 \%$ & $47 \%$ & $23 \%$ \\
\hline 8 & Blackberry Messenger & $28 \%$ & $38 \%$ & $10 \%$ \\
\hline 9 & Linkedin & $16 \%$ & $33 \%$ & $17 \%$ \\
\hline 10 & Skype & $15 \%$ & $28 \%$ & $13 \%$ \\
\hline 11 & Wechat & $14 \%$ & $28 \%$ & $14 \%$ \\
\hline \multicolumn{2}{|l|}{ Jumlah Pengguna } & $\pm 130 \mathrm{Juta}$ & $\pm 150 \mathrm{Juta}$ & $20 \%$ \\
\hline
\end{tabular}

Berdasarkan hasil riset tersebut Youtube sebagai media sosial mendapatkan tingkat popularitas yang tinggi di Indonesia. ${ }^{5}$ Pada sisi media dakwah Youtube telah membuat para pendakwah mendapatkan popularitas di tengah masyarakat. Aktifitas dakwah pun bisa dikemas dengan nuansa yang milenial, bahkan hasil digitalisasi dakwah tersebut bisa ditransfer ke dalam berbagai media sosial lainnya.

Tapi perlu digarisbawahi bahwa, kebebasan dalam men-digitalisasi dakwah dan menyebarkannya (sharing/publshing) melalui Youtube seringkali kebablasan. Isi atau konten dakwah terkadang memuat pesan-pesan yang tidak memiliki keterkaitan dengan dakwah secara substansial. Sebagai contoh kasus yang dialami oleh beberapa pendakwah seperti Ustadz Teuku Zulkarnain, Ustadz Sugi Nur Raharja, dan yang terbaru adalah Ustadz Rahmat Baequni. Kasus tersebut berawal dari pesan-pesan argumentatif yang bersifat isu politis dan provokatif masuk ke dalam aktifitas dakwah. Pada akhirnya dakwah tersebut tersebar di media sosial dan dampaknya akan dipercaya bagi para penggemar dakwahnya.

Oleh karena itu, penelitian pada artikel ini akan menganalisis beberapa karakteristik channel Youtube dakwah dan aktifitasnya dalam mengorganisir, mendesain,

5 We Are Social, "Indonesia Digital Report 2018", Andi Dwi Rianto (09 Februari 2018), https://andi.link/hootsuite-we-are-social-indonesian-digital-report-2018/, diakses pada 13 Juni 2018. 
Mawa'izh

Jurnal Dakwah dan Pengembangan Sosial Kemanusiaan

Vol. 9, no. 2 (2018), pp. 224-

dan mempublikasikan dakwah. Sumber data dalam penelitian ini terbagi menjadi dua, pertama; sumber data primer yang terdiri dari channel Youtube yang hendak diteliti, afiliasi terhadap organisasi dan konteks ceramah tersebut diproduksi. Kedua; sumber sekundernya atau data pendukung, adalah buku atau kajian-kajian lain yang membahas tentang fenomena media massa, internet dan kehidupan agama di era digital. Sumber pendukung lainnya ialah keberadaan media sosial yang mengkonstruksi, mereproduksi dan menyebarkan kembali ceramah-ceramah para $d a^{\prime} i$ tersebut.

Pendekatan yang digunakan dalam artikel ini pendekatan media melihat framing media dalam mereproduksi konten. Analisis konten dalam tulisan ini terfokus pada; 1) Pendekatan partisipasi budaya media (participatory culture) yang digagas oleh Henri Jenkins untuk menganalisa karakteristik channel Youtube dakwah, dan bagaimana pengguna atau pengelola channel Youtube dakwah (Youtubers) bebas mengkonstruksi channel Youtube-nya; 2) Pendekatan dampak media baru (new media).

\section{B. Aktivitas Dakwah di Media Sosial (Channel Youtube)}

Dakwah sebagai kewajiban harus mampu dilaksanakan secara terus-menerus dan metode penyampaiannya disesuaikan dengan perkembangan zaman. Meskipun peradaban zaman selalu berkembang, maka misi dakwah untuk membumikan Islam yang rahamatan lil 'alamin harus tetap terwujud. Oleh karena itu, para pendakwah dalam mengaktualisasikan dakwahnya harus memahami bahwa konten dan bentuk dakwah merupakan bagian yang tidak terpisah, namun dapat dibedakan dalam konsep dakwah. Sedangkan karakteristik, strategi penyampaian dan metode dakwah juga memiliki kedudukan yang penting dalam dakwah. ${ }^{6}$

Namun di era revolusi industri 4.0 setiap orang bisa berdakwah seperti seorang da'i atau penceramah, karena dakwah bisa dilaksanakan dimanapun dan oleh siapapun, atas dasar amar ma'ruf nahi munkar. ${ }^{7}$ Selain itu, aktivitas dakwah harus memenuhi beberapa syarat, diantaranya pesan-pesan dakwah harus tepat, mengenal psikologis mad'u, mampu menggunakan metode yang representatif, dan berperilaku yang bijaksana.

Patut disadari bahwa aktualisasi dakwah digital tersebut memberikan suatu paradigma baru mengenai aktivitas dakwah bermedia sosial. Kedudukan da'i bukan lagi

${ }^{6}$ Muhyiddin, Asep Muhyidin dan Ahmad Safei, Metode Pengembangan Dakwah (Bandung: Pustaka Setia, 2002), p. 25-6.

${ }^{7}$ Acep Aripudin, Pengembangan Metode Dakwah (Jakarta: Raja Grafindo Persada, 2011), p. 4. 
sebagai subjek utama yang menyampaikan pesan-pesan dakwah secara maksimal kepada mad'u, karena dalam konteks masyarakat informasi, mad'u tidak pasif dan mereka mampu mengolah pesan dakwah tersebut untuk didistribusikan lag dalam bentuk konten digital. Perangkat media sosial dalam lingkup media baru tersebut juga memberikan kedudukan bagi pengguna ( $d a^{\prime} i$ atau mad'u) untuk mengolah informasi.

Senada dengan apa yang diungkap oleh McQuail dalam Ardianto yang menguraikan ciri-ciri utama media baru (media sosial) perspektif pengguna (user), yaitu: 1. Interactivity; berupa inisiatif dari pengguna terhadap tawaran dari sumber atau pengirim pesan;

2. Social presence (sociability); Media dapat menjembatani perbedaan kerangka referensi, mengurangi ambiguitas, memberikan isyarat-isyarat, lebih peka dan lebih personal;

3. Autonomy; pengguna media merasa dapat mengendalikan isi dan menggunakannya dan bersikap independen terhadap sumber;

4. Playfulness; digunakan untuk hiburan dan kenikmatan;

5. Privacy; diasosiasikan dengan penggunaan medium dan atau isi yang dipilih;

6. Personalization; tingkatan dimana isi dan penggunaan media bersifat personal dan unik. ${ }^{8}$

Pada konteks penggunaan channel Youtube sebagai media dakwah digital, para pengguna memiliki posisi yang sama untuk mengolah dan mendistribusi pesan-pesan dakwah yang telah terdigitalisasi berbentuk video. Youtube adalah cara tercepat dan memiliki daya pikat yang sangat siginifikan bagi pola dakwah di ranah media sosial.

Ada fitur (fasilitias produk digital) channel pada Youtube, Kotler \& Keller mengemukakan bahwa, fitur merupakan karakteristik suatu produk yang menjadi pelengkap fungsi dasar produk baik yang bersifat konvensional maupun digital. ${ }^{9}$ Sebagai produk digital Youtube memiliki fitur channel, fitur ini berfungsi seperti saluran siaran pada televisi atau pada siaran radio. Pada channel ini pengguna dapat mengunggah (upload) video, mengorganisir channelnya, memberi respon melalui kolom komentar terhadap video pengguna lain, membuat pengelompokan video sendiri, melihat data statistik pengunjung channel (viewers) atau melakukan editing video yang terdapat pada channel mereka.

\footnotetext{
${ }^{8}$ E. Ardianto, Komunikasi Massa Suatu Pengantar (Bandung: Simbiosa Rekatama, 2011), p. 14
}

${ }^{9}$ Kotler and Keller, Marketing Management (Global Edition: Pearson Prentice Hall, 2012), p. 8. 
Selain itu ada fitur yang menarik bagi para penggemar dan pengunjung utama (subscriber) yang memberi respon terhadap kesukaannya pada channel tersebut. Fitur itu dapat berdampak pada sisi bisnis dakwah yang menghasilkan profit. Semakin banyak mendapatkan subcriber dan jumlah tayang yang semakin tinggi, maka akan semakin banyak pula mendapatkan poin dalam google adsense (layanan periklanan dari Google).

Gambar 1.

Channel Youtube dengan label dakwah

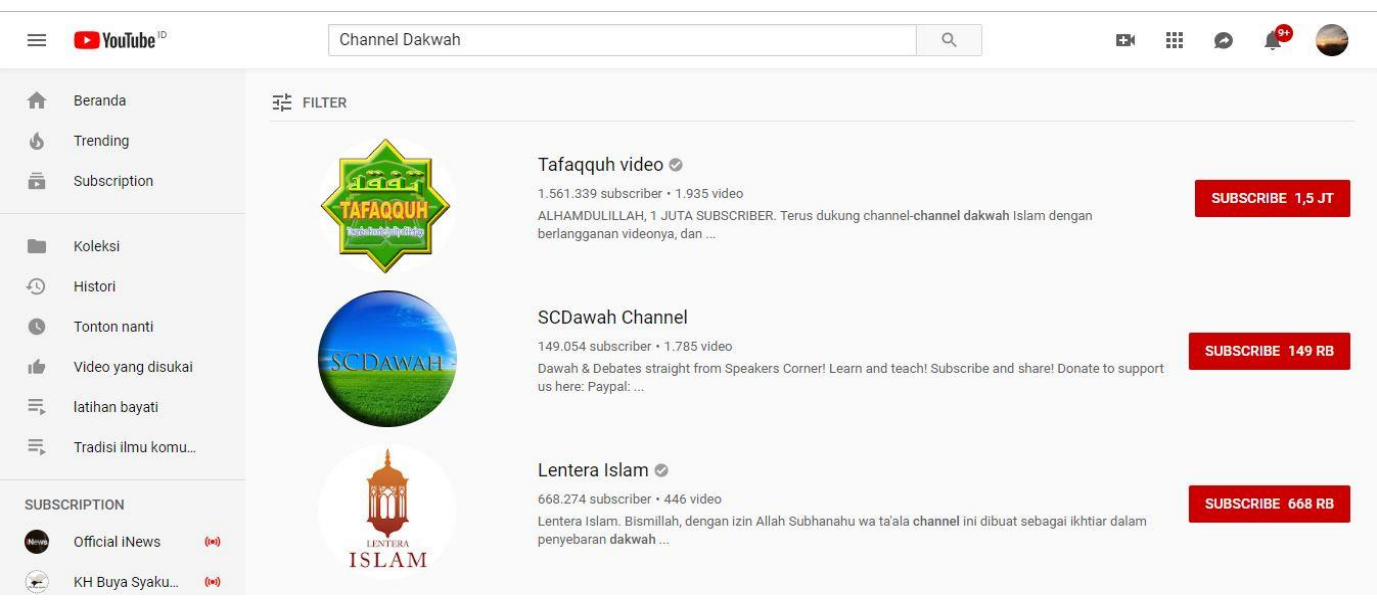

Karakteristik channel Youtube dakwah ditinjau dengan pendekatan budaya partisipasi (participatory culture) yang dikembangkan oleh Henry Jenkins memberi kejelasan bahwa, budaya partisipasi adalah konsep memahami peran dan berpartisipasi secara aktif dalam menghasilkan, memilih, memilah, dan memaknai perilaku masyarakat dalam suatu komunitas.

Bentuk budaya partisipasi menurut Jenkins terdiri dari empat jenis, yaitu afiliasi, ekspresi, kolaborasi pemecahan masalah, dan sirkulasi. Pertama; afiliasi (affiliations) merupakan bentuk budaya partisipasi berupa pengabungan diri secara formal maupun informal dalam sebuah komunitas online maupun ofline. Kedua; ekspresi (expressions) yaitu bentuk budaya partisipasi yang bukan hanya sekedar komunikasi melainkan menungkan sebuah ekspresi dalam bentuk-bentuk kreativitas baru.

Ketiga; kolaborasi pemecahan masalah (collaborative problem solving). Kolaborasi pemecahan masalah merupakan bentuk budaya partisipasi yang ditandai dengan adanya bentuk kerjasama dalam suatu kelompok baik secara formal maupun informal untuk mengembangkan pengetahuan baru. Keempat; sirkulasi (circulations). Sirkulasi ini merupakan bentuk budaya partisipasi yang mana merupakan aktivitas 
membentuk aliran informasi di dalam media untuk mempertajam informasi di dalamnya. ${ }^{10}$

Berdasarkan analisa melalui pendekatan partisipasi budaya media, ada beberapa aktivitas dakwah yang dilakukan oleh para da'i yang terafiliasi dengan unsur organisasi kemasyarakatan yang ada di Indonesia. Lebih jelasnya dapat dilihat pada tabel berikut:

Tabel 2.

Afiliasi $d a^{\prime} i$ dengan channel Youtube yang dikelola organisasi kemasyarakatan.

\begin{tabular}{|c|c|c|c|}
\hline No & Nama Channel Youtube & Dominasi Pendakwah & Subscriber \\
\hline 1 & NU Channel & $\begin{array}{l}\text { 1. Prof. Dr. KH. Said Aqil Siradj } \\
\text { 2. Prof. Dr. KH. Ma'ruf Amin } \\
\text { 3. Habib Lutfi bin Yahya } \\
\text { 4. Gus Muwafiq } \\
\text { 5. KH. A. Mustofa Bisri } \\
\text { 6. Dr. KH. Lukman Hakim } \\
\text { 7. Habib Syech Bin Abdul Qadir Assegaf } \\
\text { 8. KH. Dr. Nasrullah Affandi }\end{array}$ & 142.421 \\
\hline 2 & $\begin{array}{c}\text { Muhammadiyah } \\
\text { Channel }\end{array}$ & Dr. H. Haedar Nasir & 1.672 \\
\hline 3 & Front TV (FPI) & $\begin{array}{l}\text { 1. Ustadz Gilang Ghifari } \\
\text { 2. Habib Ali bin Jindan } \\
\text { 3. KH. Awit Mashuri }\end{array}$ & 265.383 \\
\hline 4 & Persis Channel & $\begin{array}{l}\text { 1. KH. M. Romli } \\
\text { 2. Drs. Uus M. Ruhiat } \\
\text { 3. Ustad. Gugum Gunawan }\end{array}$ & 4.126 \\
\hline 5. & $\begin{array}{l}\text { NW TV Online } \\
\text { (Nahdlatul Wathan) }\end{array}$ & $\begin{array}{l}\text { 1. Prof. Dr. Fahrurozi Dahlan } \\
\text { 2. H. Ahmad Zikri } \\
\text { 3. Ustad. Azhar Harif } \\
\text { 4. TGH. Fuad Zaini, QH. }\end{array}$ & 9.669 \\
\hline
\end{tabular}

Sumber: Dirangkum dan dianalisis dari tingkat keaktifan unggahan video pada channel Youtube (akses laman youtube.com) yang dikembangkan oleh beberapa organisasi kemasyarakatan yang ada di Indonesia. Diakses terakhir pada 13 Juni 2018.

Selain itu pada pendekatan ekpresi budaya media (expressions) ada beberapa penguna Youtube (Youtuber) yang ikut serta melibatkan diri dalam pendistribusian video dakwah. Pengguna tersebut menggunakan daya kreatifitasnya untuk mengemas ulang

10 Henry Jenkins, Purushotma Ravi, Weigel Margaret, Katle Clinton, and Alice J. Robinson, Confronting the Challenges of Participatory Culture: Media Education for the 21st Century. (Massachusetts: MIT Press, 2009), p. 8. 
sajian video tersebut ke dalam bentuk video yang lebih menarik. Pada aktifitas ini pemilik channel tersebut bebas mengemas unggahan videonya. Ada penambahan design grafis, penguatan teks, dan kata kunci dakwah tersebut.

Tabel 3.

Beberapa kreatifitas Youtuber dalam mengemas konten dakwah

\begin{tabular}{|c|l|c|c|l|}
\hline No & Channel Youtube & Subscriber & $\begin{array}{c}\text { Rata-rata } \\
\text { Penayangan } \\
\text { (rbx)/Minggu }\end{array}$ & \multicolumn{1}{|c|}{ Konten Dakwah } \\
\hline 1 & Semoga Berkah & 387.468 & $2 \mathrm{rbx}$ & $\begin{array}{l}\text { Ringkasan ceramah } \\
\text { Ustad. Adi Hidayat }\end{array}$ \\
\hline 2 & Ki Rafindra & 107.059 & $1,5 \mathrm{rbx}$ & $\begin{array}{l}\text { Ringkasan ceramah Kyai. } \\
\text { Anwar Zahid }\end{array}$ \\
\hline 3 & $\begin{array}{l}\text { Ceramah } \\
\text { Inspiratif }\end{array}$ & 76.491 & $1 \mathrm{rbx}$ & $\begin{array}{l}\text { Ringkasan ceramah Alm. } \\
\text { KH. Zainudin. MZ }\end{array}$ \\
\hline 4 & Santri Gayeng & 29.382 & $1 \mathrm{rbx}$ & $\begin{array}{l}\text { Ringkasan ceramah Gus } \\
\text { Baha }\end{array}$ \\
\hline
\end{tabular}

Sumber: Data tersebut dipilih berdasarkan tipe pengelolaan Youtube secara personal dan bukan bagian dari institus organisasi. Diakses terakhir pada 13 Juni 2018.

Gambar 3.

Kemasan dakwah dalam channel Youtube Semoga Berkah

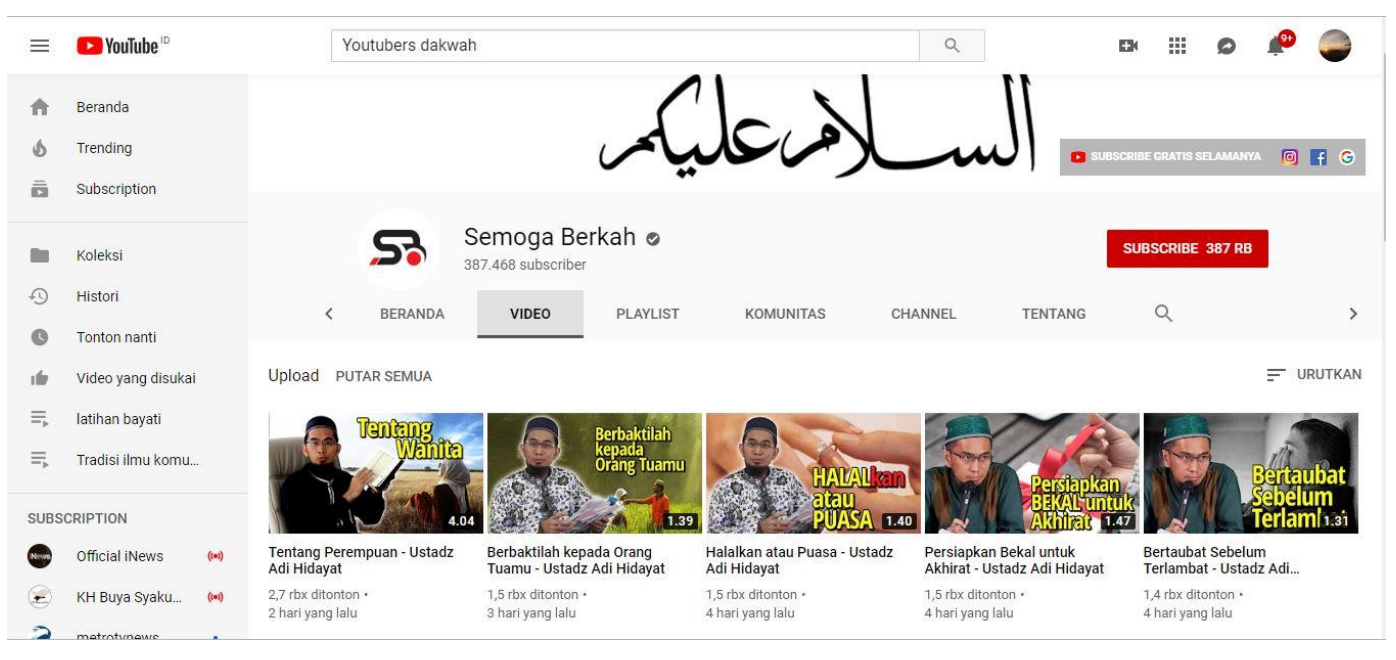

Selanjutnya pada pendekatan kolaborasi pemecahan masalah (collaborative problem solving) ada beberapa komunitas channel dakwah yang secara spesifik menyajikan dan menayangkan aktifitas dakwah dalam berbagai bentuk. Ada dakwah interaktif, kultum, sajian murottal, tabligh akbar, dan pengajian (tanya jawab persoalan agama). Lebih jelasnya dapat dilihat pada tabel berikut: 
Tabel 4.

Komunitas channel dakwah dengan jumlah subscriber tertinggi

\begin{tabular}{|c|l|c|c|l|}
\hline No & Channel Youtube & Subscriber & $\begin{array}{c}\text { Rata-rata } \\
\text { Penayangan } \\
\text { (rbx)/Minggu }\end{array}$ & \multicolumn{1}{|c|}{ Konten Dakwah } \\
\hline 1 & Tafaquh Video & 1.564 .438 & $25 \mathrm{rbx}$ & $\begin{array}{l}\text { Ringkasan ceramah Ustad } \\
\text { Abdul Shomad }\end{array}$ \\
\hline 2 & $\begin{array}{l}\text { Taman Surga. } \\
\text { Net }\end{array}$ & 1.266 .768 & $20 \mathrm{rbx}$ & $\begin{array}{l}\text { Ringkasan ceramah Ustad } \\
\text { Abdul Shomad }\end{array}$ \\
\hline 3 & Ammar TV & 1.423 .744 & $15 \mathrm{rbx}$ & Murottal dan Tahsinul Qur'an \\
\hline 4 & Yufid TV & 1.196 .054 & $12 \mathrm{rbx}$ & Aspek Ibadah- Syariah \\
\hline 5 & Bahjah TV & 986.198 & $10 \mathrm{rbx}$ & Tanya Jawab \\
\hline
\end{tabular}

Sumber: Data tersebut dipilih berdasarkan konten video dakwah yang muatannya berisi tanya jawab, dakwah interaktif, sepesifikasi pada formalisme ajaran, dan jumlah subcriber tertinggi. Diakses terakhir pada tanggal 15 Juni 2018

Gambar 4.

Contoh salah satu channel Youtube dakwah

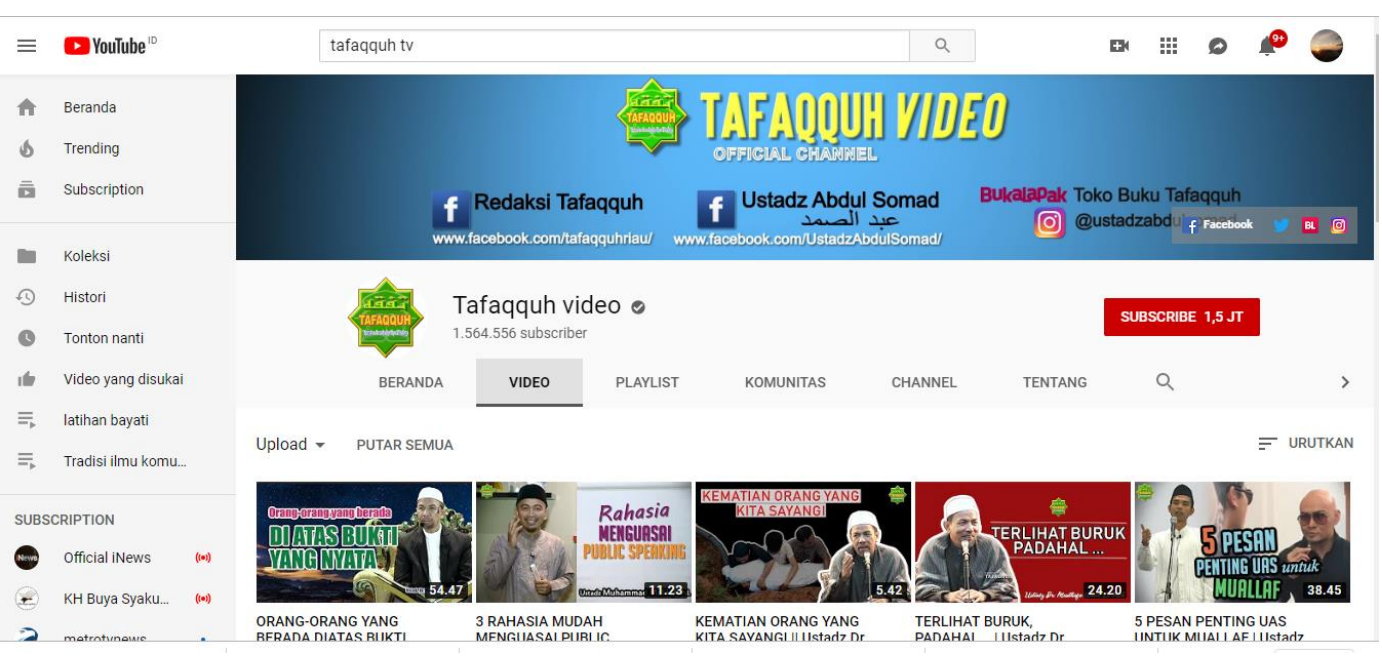

Ditinjau berdasarkan pendekatan sirkulasi media (circulations), nampak beberapa para dai berhasil menguasi ruang dakwah digital mereka melalui channel youtube dakwah (official). Segala bentuk aktifitas dakwah mereka di ruang publik (pengajian, majelis taklim, seminar, dan lain-lain) menjadi bahan atau materi aktivitas dakwah yang akan langsung di-digitalisasi dalam format video dan diunggah ke channel Youtube mereka. Sejauh ini channel Youtube Gus Muwafiq Officcial dan Adi Hidayat Official mendapatkan jumlah penayangan yang cukup tinggi dibandingkan dengan channel dakwah lainnya. Lebih jelas dapat dilihat pada tabel berikut: 
Tabel 5.

Pendakwah populer dengan personalisasi channel Youtube dakwah "official"

\begin{tabular}{|c|l|c|c|}
\hline No & \multicolumn{1}{|c|}{ Channel Youtube Official } & Subscriber & $\begin{array}{c}\text { Rata-rata } \\
\text { Penayangan } \\
\text { (rbx)/ Minggu }\end{array}$ \\
\hline 1 & Gus Muwafiq Official & 115.916 & $30 \mathrm{rbx}$ \\
\hline 2 & Adi Hidayat Official & 114.807 & $20 \mathrm{rbx}$ \\
\hline 3 & Khalid Basalamah Official & 934.959 & $10 \mathrm{rbx}$ \\
\hline 4 & Syafiq Riza Basalamah Official & 339.774 & $10 \mathrm{rbx}$ \\
\hline 5 & Aagym Official & 148.710 & $5 \mathrm{rbx}$ \\
\hline 6 & Yusuf Mansur Official & 23.942 & $2 \mathrm{rbx}$ \\
\hline 7 & Gus Miftah Official & 64.123 & $1 \mathrm{rbx}$ \\
\hline
\end{tabular}

Sumber: Data tersebut diambil berdasarkan jumlah penayangan yang tinggi dan channel tersebut dikelola oleh tim official yang dibentuk dan dikembangkan atas izin dari $d a^{\prime} i$ tersebut. Diakses terakhir pada tanggal 15 Juni 2018.

Gambar 5.

Personalisasi channel Youtube dakwah

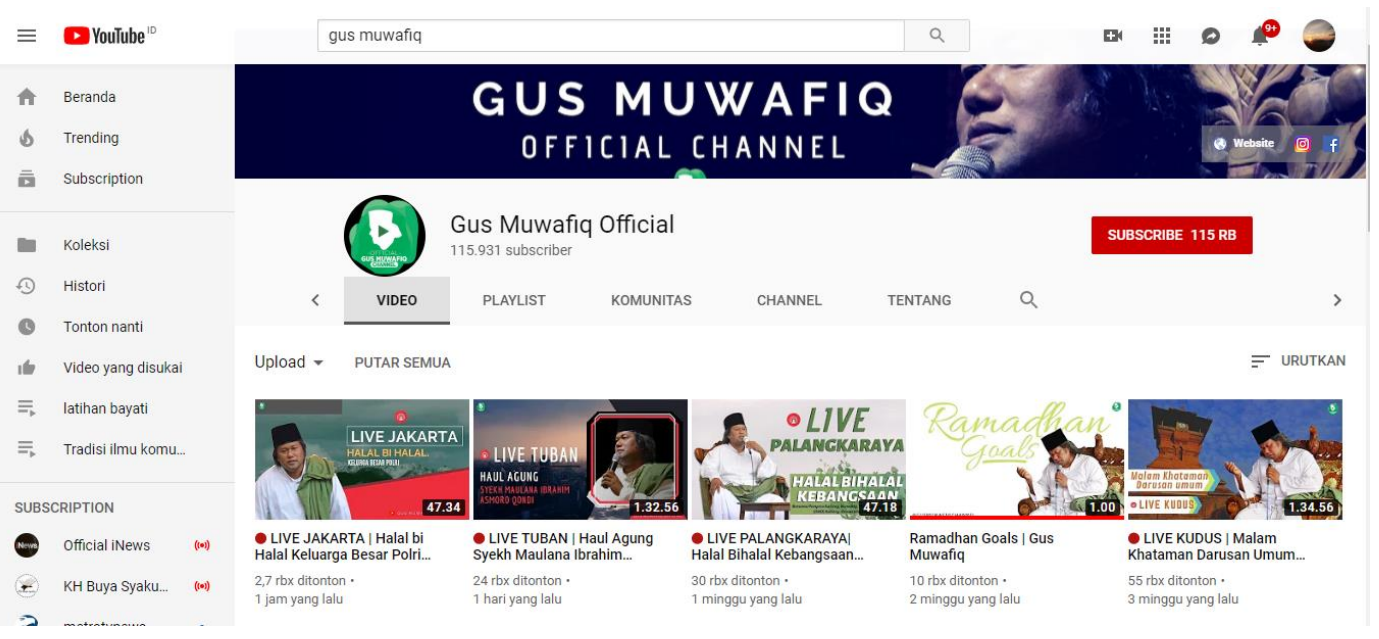

\section{Da'i dan Mad'u Milenial: Ancaman di Balik Kebebasan Berdakwah}

Realitas dakwah di era revolusi industri 4.0 selalu dihadapkan pada dua sisi yang saling bertentangan, ada peluang dan ancaman. Kemudahan akses dan keterbaruan perangkat teknologi berhasil mentransformasi seorang $d a^{\prime} i$ menjadi $d a^{\prime} i$ yang milenial. Da'i milenial dapat diidentikkan dengan tingginya aktifitas dakwah yang dilakukannya di media sosial. Da'i milenial memiliki kebebasan dalam mengekspresikan dakwahnya di media sosial. Dalam ranah sosial $d a^{\prime} i$ milenial dapat fokus menanggapi setiap persoalan 
dan kejadian-kejadian yang mengarah pada status hukum yang sesuai dengan koridor Islam.

Ada banyak peluang dakwah yang bisa diraih oleh para $d a^{\prime} i$ milenial di media sosial. McLuhan secara spesifik menegaskan bahwa "The medium is the message", yang dimaknai bahwa media adalah pesan yang mengarah pada aktualitas media sosial di tengah masyarakat. Media dipahami sebagai perluasan dari kemampuan manusia dalam menerima rangsangan. ${ }^{11}$ Oleh karena itu, dengan menggunakan media sosial para da'i dapat berkomunikasi dan berinteraksi secara langsung dengan mad'u-nya. Disinilah interaksi antara da'i dan mad'u milenial terbangun.

Namun dibalik kebebasan itu, da'i milenial harus menyadari ancamannya, bahwa pemanfaatan media sosial dan kontrol terhadap media tersebut masih belum jelas. Sehingga dibalik kebebasan tersebut $d a^{\prime} i$ tidak ceroboh. Ada banyak kasus yang menimpa para da'i dikarenakan konten dakwahnya tidak substansial dengan pesan dakwah, dan mengandung pesan provokatif. Berikut beberapa para $d a^{\prime} i$ yang terjerat kasus hukum karena video dakwahnya memuata unsur Suku, Agama, Ras, dan Antargolongan (SARA) dan fitnah.

Tabel 6.

Pendakwah yang terjerat kasus hukum akibat tindakan provokatif dan fitnah

\begin{tabular}{|c|c|c|c|}
\hline No & Pendakwah & Kasus Hukum & Sumber \\
\hline 1 & $\begin{array}{l}\text { Teuku } \\
\text { Zulkarnain }\end{array}$ & $\begin{array}{l}\text { Pesan Provokatif } \\
\text { Terkait isu legalistas UU Zina } \\
\text { dan isu politik. }\end{array}$ & $\begin{array}{l}\underline{\text { https://news.detik.com/berita/ }} \\
\text { d-4371147/dipolisikan-tengku- } \\
\text { zul-siap-jelaskan-soal-cuitan- } \\
\underline{\text { surat-suara-tercoblos }}\end{array}$ \\
\hline 2 & $\begin{array}{l}\text { Habib } \\
\text { Bahar bin } \\
\text { Smith }\end{array}$ & $\begin{array}{l}\text { Tindakan kekerasan dan } \\
\text { pesekusi. }\end{array}$ & $\begin{array}{l}\text { https://jateng.tribunnews.com/ } \\
\text { 2019/05/24/akhirnya-habib- } \\
\text { bahar-bin-smith-ungkap-alasan- } \\
\text { aniaya-2-remajadia-mengakui- } \\
\text { istri-saya-itu-harga-diri }\end{array}$ \\
\hline 3 & $\begin{array}{l}\text { Sugi Nur } \\
\text { Raharja }\end{array}$ & Ujaran kebencian & $\begin{array}{l}\text { https://www.merdeka.com/per } \\
\text { istiwa/sidang-ujaran- } \\
\text { kebencian-sugi-nur-sempat- } \\
\text { diwarnai-kericuhan.html }\end{array}$ \\
\hline 4 & $\begin{array}{l}\text { Rahmat } \\
\text { Baequni }\end{array}$ & Fitnah & $\begin{array}{l}\text { https://news.okezone.com/rea } \\
\text { d/2019/06/21/525/2069096/ } \\
\text { ustadz-rahmat-baequni- } \\
\text { ditangkap-polisi-terkait-hoax- } \\
\text { kpps-meninggal-diracun }\end{array}$ \\
\hline
\end{tabular}

11 Jalaluddin Rakhmat, Psikologi Komunikasi, (Bandung: Rosda, 2008), p. 220 
Oleh karena itu, pemanfaatan media sosial oleh para $d a^{\prime} i$ harus menjunjung tinggi prinsip bil-hikmah yang penuh dengan kearifan dan kebijaksanaan. Menggunakan media sosial secara arif dan tepat guna akan memudahkan seseorang untuk mendapatkan pengajaran, pengetahuan, dan pemecahan masalah. Sebaliknya jika memanfaatkan media sosial dengan bebas tanpa batasan etika komunikasi dakwah, maka berakibat pada halhal negatif dan merugikan.

Perangkat hukum telah mengatur dalam Undang-undang Informasi dan Transaksi Elektronik yang secara tegas menjelaskan perbuatan yang dilarang dalam memanfaatkan media sosial. Seperti; percemaran nama baik diatur pada pasal 27 ayat 3 . Begitu juga larangan membuat pernyataan yang provokatif dan mengandung unsur SARA dijelaskan pada pasal 28 ayat 2; "Setiap Orang dengan sengaja dan tanpa hak menyebarkan informasi yang ditujukan untuk menimbulkan rasa kebencian atau permusuhan individu dan/atau kelompok masyarakat tetentu berdasarkan atas SARA.

Selain berdampak pada aspek hukum. Kesalahan dalam mengkosntruksi dakwah di channel Youtube akan berdampak pula pada pola perilaku mad'u milenial. Tingkat popularitas $d a^{\prime} i$ di media sosial akan menjadi daya pikat bagi pengagumnya

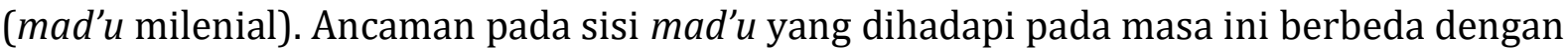
generasi sebelumya (generasi lama), melainkan ancaman dari generasi digital native yang sangat ketergantungan dengan benda-benda teknologi tinggi, sehingga masuk ke dalam pola interaksi sosial yang berbasis teknologi (tekno-sosial).

Mad'u milenial yang identik dengan generasi digital native, mereka menganggap bahwa media sosial adalah bagian yang sangat penting dan dibutuhkan bagi kehidupan mereka. Bahkan media sosial dianggap sebagai teman hidup yang sulit untuk dipisahkan.12 Inilah ancaman bagi $d a^{\prime} i$ sekaligus mad'u dalam aktifitas dakwah. Hasil survei APJII pada tahun 2018 yang dirilis dalam penetrasi pengguna media sosial di Indonesia menyebutkan rentang usia 15- 34 tahun memiliki tingkat konsumsi media yang tinggi atau sekitar $91 \%$ dari seluruh total pengguna internet di Indonesia. ${ }^{13}$

Ditinjau dari analisis media dakwah, maka perlu ada upaya pengawasan dakwah (controlling) dalam menanggapi berbagai kesalahan pendakwah di channel

12 R. Mardina, "Potensi Digital Natives dalam Representasi Literasi Informasi Multimedia Berbasis Web di Perguruan Tinggi”, Jurnal Pustakawan Indonesian, Vol. 11, no. 1 (2011), p. 14.

13 APJII, "laporan Survei Penetrasi dan Profil Perilaku Pengguna Internet Indonesia, Asosiasi Penyelenggara Jasa Internet Indonesia, 2018. 
Youtube. Pengawasan dakwah ini bertujuan untuk mengidentifikasi berbagai kesalahan dalam memahami agama. Sehingga tercapai misi dakwah yang humanis dan rahmatan lil 'alamin. Ada beberapa contoh pelaksanaan pengawasan dakwah yang dilakukan oleh beberapa $d a^{\prime} i$ di channel Youtube, diantaranya channel Youtube Harisun Abd Hadi (Ustadz Kampung), channel Youtube KH. Buya Syakur, MA., channel Youtube Agama Akal.

Pada channel tersebut para $d a^{\prime} i$ mengkaji dan menganalisis argumentasi dan kajian dakwah yang disampaikan oleh $d a^{\prime} i$ lainnya di channel Youtube yang berbeda. Koreksi itu mereka jelasakan melalui pendekatan studi Islam, dan dibantah dengan dalildalil yang terperinci.

\section{Simpulan}

Media sosial adalah bagian penting dari media dakwah kontemporer, dengan kebebasan akses jaringan yang luas dan cepat sangat potensial untuk mencapai kesuksesan dakwah. Akan tetapi, media sosial sebagai perangkat teknologi memiliki dua dampak dalam penggunaanya, ada dampak positif dan negatif. Kebebasan berekpresi dan mengolah pesan-pesan dakwah secara digital jangan dimaknai sebagai kebebasan tanpa batas.

Kebebasan akses tersebut harus diwaspadai sebagai ancaman dakwah. Apalagi pesan-pesan dakwah yang bermuatan fitnah, provokasi, dan menganut pemahaman agama yang radikal dan intoleran, lalu terkonstruksi secara digital dan disebarluaskan ke mad'u milenial (digital natives). Hal tersebut akan sangat berbahaya bagi tercapainya misi dakwah yang rahmatan lil 'alamin.

Oleh karena itu para da'i milenial harus kembali pada karakteristik $d a^{\prime} i$ yang sesungguhnya, yakni da'i yang humanis, transformatif, korektif, dan peka terhadap tantangan zaman. Selain itu, harus secara stimultan dan berkesinambungan melakukan pengawasan konten dakwah di berbagai channel Youtube. Sehingga dapat menangkal pemahaman agama yang formalis dan cenderung pada dakwah takfiri. 


\section{DAFTAR PUSTAKA}

APJII, "laporan Survei Penetrasi dan Profil Perilaku Pengguna Internet Indonesia", Asosiasi Penyelenggara Jasa Internet Indonesia, 2018.

Ardianto, E, Komunikasi Massa Suatu Pengantar, Bandung: Simbiosa Rekatama, 2011.

Aripudin, Acep, Pengembangan Metode Dakwah, Jakarta: Raja Grafindo Persada, 2011)

Baidu, Jelajah Dunia Mobile di Indonesia (Jakarta: Baidu Indonesia, 2014)

Jenkins, Henry, Ravi Purushotma, Margaret Weigel, Katle Clinton, and Alice J. Robinson, Confronting the Challenges of Participatory Culture: Media Education for the 21st Century. Massachusetts: MIT Press, 2009.

Prayitno, Budi, 'Langkah Pemerintah Menangkal Diseminasi Berita Palsu,' Jurnal Wacana Kinerja: Kajian Praktis-Akademis Kinerja dan Administrasi Pelayanan Publik, vol. 20, no. 2 (2018), pp. 17-40.

Kotler and Keller, Marketing Management, Global Edition: Pearson Prentice Hall, 2012.

Mardina, R., "Potensi Digital Natives dalam Representasi Literasi Informasi Multimedia Berbasis Web di Perguruan Tinggi", Jurnal Pustakawan Indonesian, Vol. 11, no. 1, 2011.

Muhyiddin, Asep dan Safei, Ahmad, Metode Pengembangan Dakwah, Bandung: Pustaka Setia, 2002.

Rakhmat, Jalaluddin, Psikologi Komunikasi, Bandung: Rosda, 2008.

Shrock, Andrew, Myspace or Ourspace: A Media System Dependency View Of Myspace, Thesis, Florida: University Of Central Florida, 2006.

Straubhaar Joseph, Larose, Robert and Davenport, Lucinda, Media Now: Understanding, Media, Culture, and Technology, United State Of Amerika: Thomson-Wadsworth, 2010.

We Are Social, “Indonesia Digital Report 2019”, Andi Dwi Rianto 09 Februari 2018, https://andi.link/hootsuite-we-are-social-indonesian-digital-report-2018/, diakses pada 13 Juni 2018. 